\title{
STRUCTURE OF RAPIDLY QUENCHED Fe-Co-Sn-B SYSTEMS WITH VARYING Fe/Co RATIO
}

\author{
Irena Janotová - Peter Švec, Sr. - Igor Mat'ko - \\ Peter Švec, Jr. - Dušan Janičkovič — Juraj Zigo *
}

\begin{abstract}
We present a study of ferromagnetic systems based on Fe-Co-Sn-B in nanocrystalline state. Interesting magnetic properties potentially are given by the homogeneous and ultrafine structure of bcc Fe grains in amorphous structure. The effect of alloying by Sn improves the properties of resulting structure constituted be crystalline grains in amorphous matrix. The structure transformation from amorphous state was investigated by selected techniques of thermal analysis and the resulting phase and morphology of crystalline products were analyzed.
\end{abstract}

K e y w ords: metallic glasses, planar flow casting, soft magnetic materials, amorphous materials, iron-cobalt-boron alloys, nanocrystalline structure

\section{INTRODUCTION}

Nanocrystalline systems based on Fe-Co-B-Si were investigated many times in recent studies [1-4]. It was due to the useful combination of such a features like a magnetic softness potentially combined with high values of saturation induction [4-8] and also low values of saturation magnetostriction and magnetocrystalline anisotropy, given by the homogeneous and ultrafine structure of bccFe grains immersed in amorphous matrix $[6,9,10]$. Alloying of Fe-B systems by $\mathrm{Sn}$ has favorable effect on the nucleation and growth of nanocrystalline grains from amorphous matrix, [9-11] and has a potential to improve the properties mentioned above.

Amorphous samples with chemical composition $(\mathrm{Fe} / \mathrm{Co})_{96.5-x} \mathrm{Sn}_{3.5} \mathrm{~B}_{x}(x=15 ; 20$ at. \% $)$ prepared by planar flow casting were processed by isothermal annealing to investigate the structure after the first stage of transformation. Our interest was focused on the influence of the $\mathrm{Fe} / \mathrm{Co}$ ratio $2 / 1,3 / 1,1 / 1$ on the transformation parameters of these nanocrystalline systems. Stability and phase transformation parameters of the formation of phases from as-quenched amorphous structure were determined by thermal analysis. The structure and phase analyses performed by TEM and XRD reveal the character of the final crystalline products and their growth at the expense of the amorphous matrix.

\section{EXPERIMENTAL PROCEDURE}

The amorphous alloys under investigation were prepared in the form of ribbons by the planar flow casting method. The samples $6 \mathrm{~mm}$ wide and $\sim 20 \mu \mathrm{m}$ thick were linearly heated with $10 \mathrm{~K} / \mathrm{min}$ heating rate and also isothermally annealed at several selected temperatures. The sequence and products of crystallization stages of the amorphous structure at given time and temperature were thus observed. The measurements of temperature dependencies of relative electrical resistivity $R(T) / R\left(T_{0}=\right.$ $300 \mathrm{~K})$ and magnetic weight was used to obtain the basic information about the transformation behavior of the studied metallic systems. These methods enable us to define the beginning of the crystallization (temperature of onset of transformation) $T_{x}$ and to observe the character of the transformations, too. The kinetic parameters $T_{x}(10 \mathrm{~K} / \mathrm{min}), T_{c}(10 \mathrm{~K} / \mathrm{min})$ were investigated by differential scanning calorimetry (DSC7 Perkin Elmer) and by thermogravimetry with small applied magnetic field (TGA7 Perkin Elmer), both in the protective argon atmosphere. X-ray diffraction (XRD) using Bruker D8 diffractometer and transmission electron microscopy (TEM) using JEOL 2000FX were used for microstructural characterization of as-cast and isothermally annealed samples. The parameters for the heat-treatment $(723 \mathrm{~K} / 30 \mathrm{~min}$ and $783 \mathrm{~K} / 30 \mathrm{~min}$ ) were selected according to the resistivity measurements.

\section{RESULTS AND DISCUSSION}

Typical transformation of rapidly quenched materials from amorphous to nanocrystalline state usually exhibits a two-stage pattern. This can be seen by a decrease of electrical resistivity $R(T) / R\left(T_{0}=300 \mathrm{~K}\right.$ ) (Fig. 1): the two major falls of the relative electrical resistivity values indicate the two different system structure changes separated in temperature. Both can be seen as the exothermic reactions, the peaks on normalized heat flow curves (Fig. 2). Figures 1 and 2 show samples with different B

\footnotetext{
* Institute of Physics, Slovak Academy of Sciences, Dubravska cesta 9, 84511 Bratislava, Slovakia, irena.janotova@savba.sk
} 

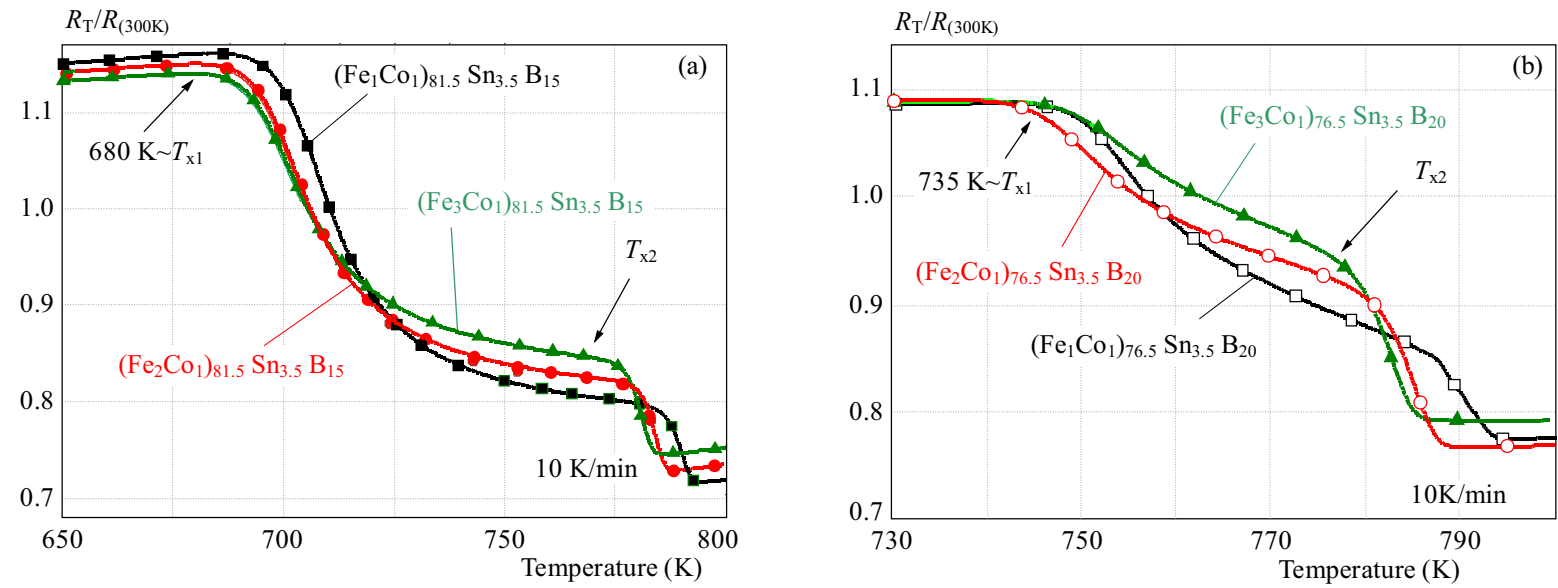

Fig. 1. Temperature dependence of the relative electrical resistivity for the systems with different Fe/Co ratio. Arrows indicate the onsets of crystallization and the temperature chosen for isothermal annealing for XRD analysis, respectively;

(a) - samples with B content 15 at. \%; (b) - samples with B content 20 at. \%
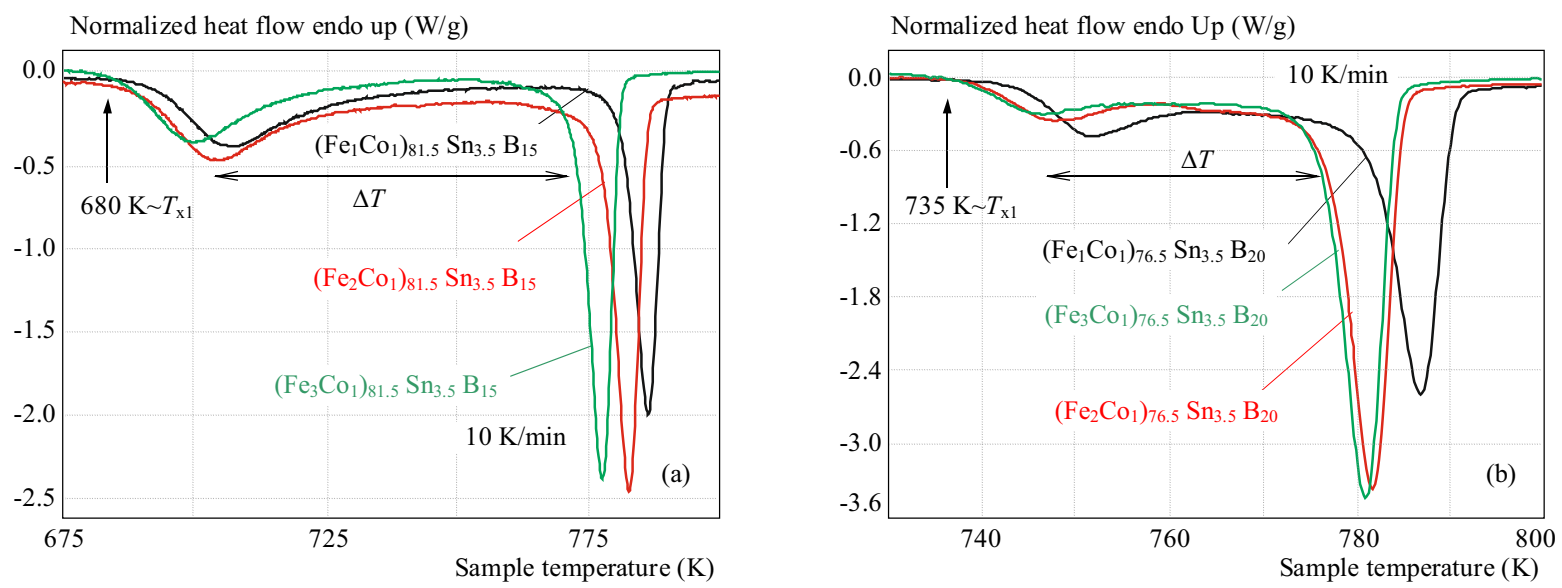

Fig. 2. Temperature dependence of the normalized heat flow from DSC measurement for the systems with different Fe/Co ratio. Arrows indicate the onsets of first crystallization $T_{x 1}$ and the temperature interval between both transformations onsets $\Delta T$, respectively; (a) - samples with B content 15 at. \%; (b) - samples with B content 20 at. \%
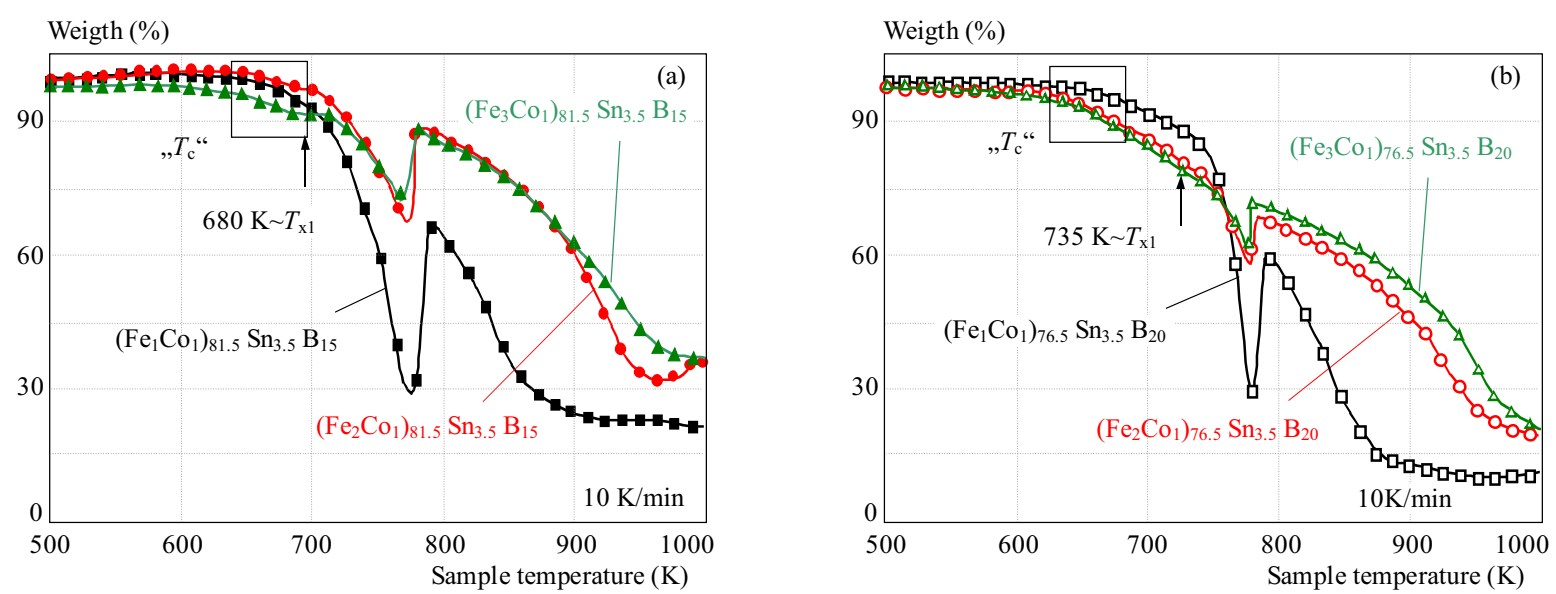

Fig. 3. TGA measurement for systems with different B content and with different Fe/Co ratio: (a) - samples with B content 15 at. $\%$; (b) - samples with B content 20 at. $\%$

content and variation of Fe/Co ratio. The onset of transformation in samples containing 15 at.\% of B is shifted towards lower temperature with increase of Fe content. The influence of $\mathrm{Fe} / \mathrm{Co}$ ratio on the transformation shape is less important in comparison with the influence of boron content. The reduction of the temperature interval between both transformations onsets $\Delta T$ (Fig. 2) due to increased content of B (higher $T_{x 1}$ for samples with 20 at.\% 


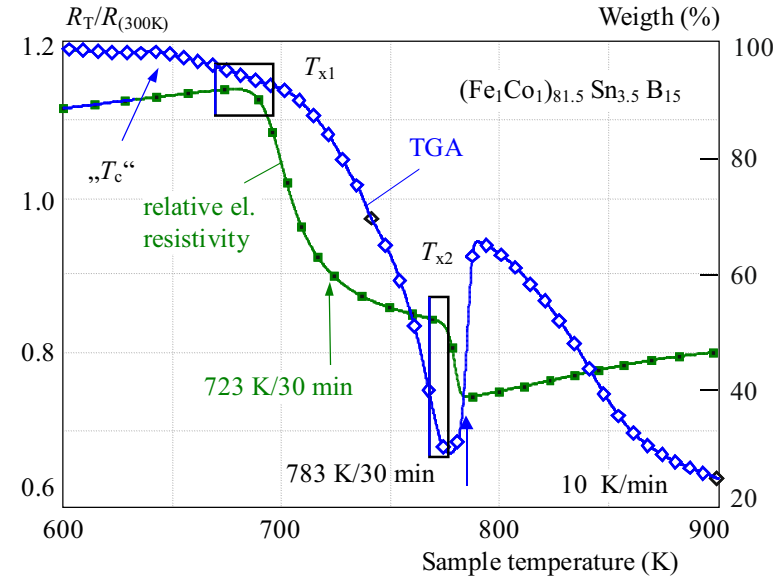

Fig. 4. TGA measurement plotted together with dependence of the relative electrical resistivity; temperatures of the transformations onset ( $\left.T_{x 1}, T_{x 2}\right)$, and a "hint" of Curie temperature (" $\left.T_{c} "\right)$ and the anealing temperature chosen for isothermal annealing for XRD analysis and TEM investigation $(723 \mathrm{~K} ; 783 \mathrm{~K} / 30 \mathrm{~min})$ are marked by rectangles and arrows, respectively
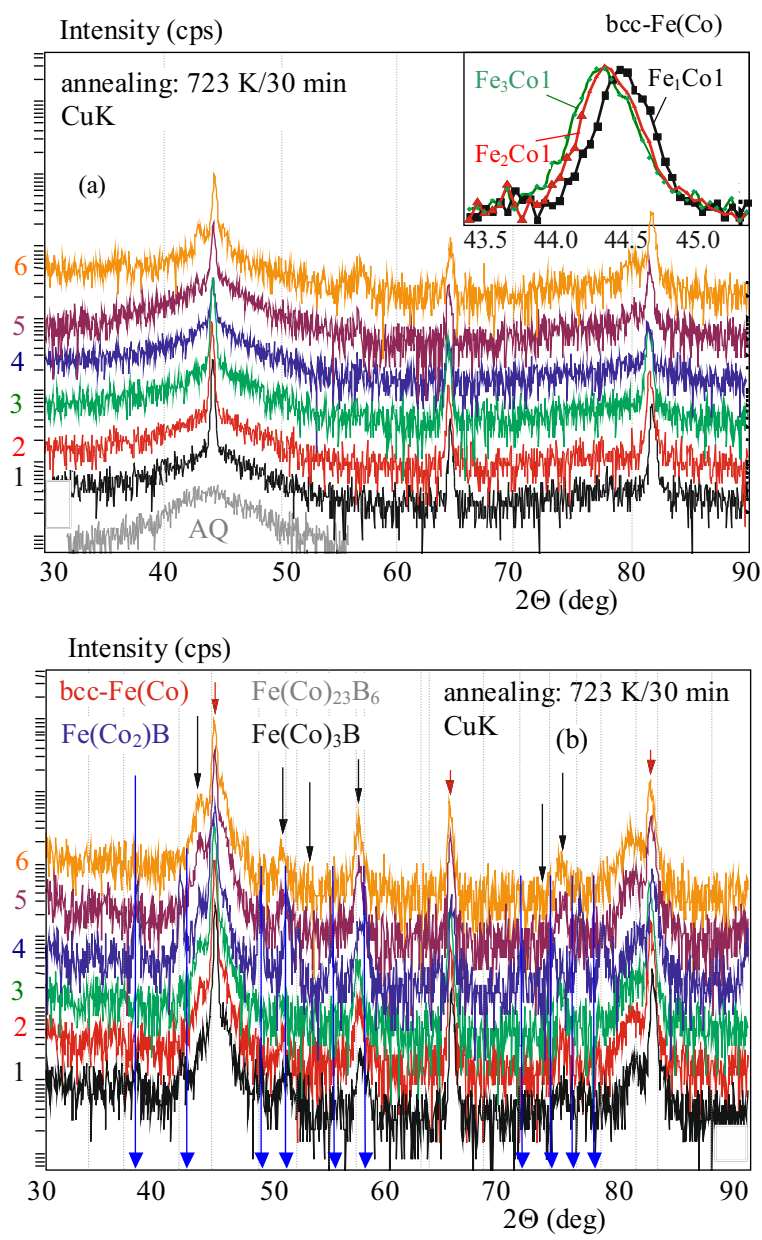

Fig. 5. XRD patterns from samples: (a) — in as-quenched amorphous state $(A Q)$ and after isothermal annealing at $723 \mathrm{~K}$ for $30 \mathrm{~min}$, (b) - after isothermal annealing at $783 \mathrm{~K}$ for $30 \mathrm{~min}$; curve: $1-\left(\mathrm{Fe}_{1} \mathrm{Co}_{1}\right)_{81.5} \mathrm{Sn}_{3.5} \mathrm{~B}_{15} ; 2-\left(\mathrm{Fe}_{2} \mathrm{Co}_{1}\right)_{81.5} \mathrm{Sn}_{3.5} \mathrm{~B}_{15}$; $3-\left(\mathrm{Fe}_{3} \mathrm{Co}_{1}\right)_{81.5} \mathrm{Sn}_{3.5} \mathrm{~B}_{15} ; 4-\left(\mathrm{Fe}_{1} \mathrm{Co}_{1}\right)_{76.5} \mathrm{Sn}_{3.5} \mathrm{~B}_{20} ;$ $5-\left(\mathrm{Fe}_{2} \mathrm{Co}_{1}\right)_{76.5} \mathrm{Sn}_{3.5} \mathrm{~B}_{20} ; 6-\left(\mathrm{Fe}_{3} \mathrm{Co}_{1}\right)_{76.5} \mathrm{Sn}_{3.5} \mathrm{~B}_{20}$

of B), is more pronounced. The onset of the second crystallization stage, $T_{x 2}$, depends only weakly on the amorphous alloy composition.
The TGA measurements (Fig. 3) show only a "hint" of Curie temperature of amorphous samples, which is located above the first crystallization stage. A slight decrease of magnetic weight at low magnetic field was observed (marked as $T_{c}$ in Figs. 3 and 4 ); however, formation of ferromagnetic phase in this temperature region prevents accurate determination of $T_{c}$ of the amorphous phase. The second stage of transformation visible as increase of weight $\%$ is clearly seen on the measured curves in Fig. 3 and reflects the crystallization of the remaining amorphous matrix into borides. Figure 4 shows a comparison of the positions of $T_{x 1}, T_{x 2}$ marked by rectangles using electrical resistivity and TGA measurements. The temperature for isothermal annealing was chosen according to the results of the thermal analysis, onto interesting points for final structure after regulated heat treatment (Fig. 4, marked by arrows).

Figure 5a shows the evolution of the metal-rich bcc$\mathrm{Fe}(\mathrm{Co})$ phase from amorphous matrix in the first crystallization stage. The formation of metalloid-rich phases from the remaining amorphous matrix takes place in the second stage (Figs. 1,2). We focused on the structure of the ferromagnetic phase formed. The inset in Fig. 5a shows the shift of the interplanar spacing of (110) bcc-Fe (Co) lattice planes due to different Co content in the lattice. The lattice parameter changes from 0.2887 down to $0.2879 \mathrm{~nm}$, reflecting the changing ratio of $\mathrm{Fe} / \mathrm{Co}$ from $3 / 1$ to $1 / 1$ [12]. The structure after annealing at higher temperature (after $T_{x 2}$ ) exhibits the presence of the bcc-Fe grains in the borides matrix. Samples with $\mathrm{Fe} / \mathrm{Co}=1 / 1$ (thick lines in Fig. 5b) exhibit $\mathrm{Fe}(\mathrm{Co})_{2} \mathrm{~B}$ phase in matrix, while the samples with higher Fe content exhibit $\mathrm{Fe}(\mathrm{Co})_{3} \mathrm{~B}$ and $\mathrm{Fe}(\mathrm{Co})_{23} \mathrm{~B}_{6}$.

It is obvious from Fig. 6 that the structure after annealing at temperature above $T_{x 1}$ consists of standard small (up to $80 \mathrm{~nm}$ ) polyhedral bcc-Fe(Co) grains surrounded by the amorphous matrix. TEM images suggest that the difference in $\mathrm{Fe} / \mathrm{Co}$ content leads only to a change in the crystallinity content while the grain size and morphology remains unaffected. A change of morphology of the bcc-Fe(Co) phase due to different Fe/Co ratio was observed after annealing at $723 \mathrm{~K} / 30 \mathrm{~min}$ for samples with 20 at. \% of boron (Fig. 7), where large irregular grains change into regular (particulate) nanograins with smaller size.

\section{CONCLUSION}

Microstructure and compositional dependence of the first transformation stage of ( $\mathrm{Fe} / \mathrm{Co}$ )-Sn-B based systems was studied. The dependence of the temperatures of crystallization onset and of the temperature interval between the first and second crystallization as well as the position of the Curie temperature relative to the first transformation was investigated. The crystallization temperature increases significantly with increased B content, but this effect is unfavorable for the stability of resulting bcc- $\mathrm{Fe}(\mathrm{Co})$ 

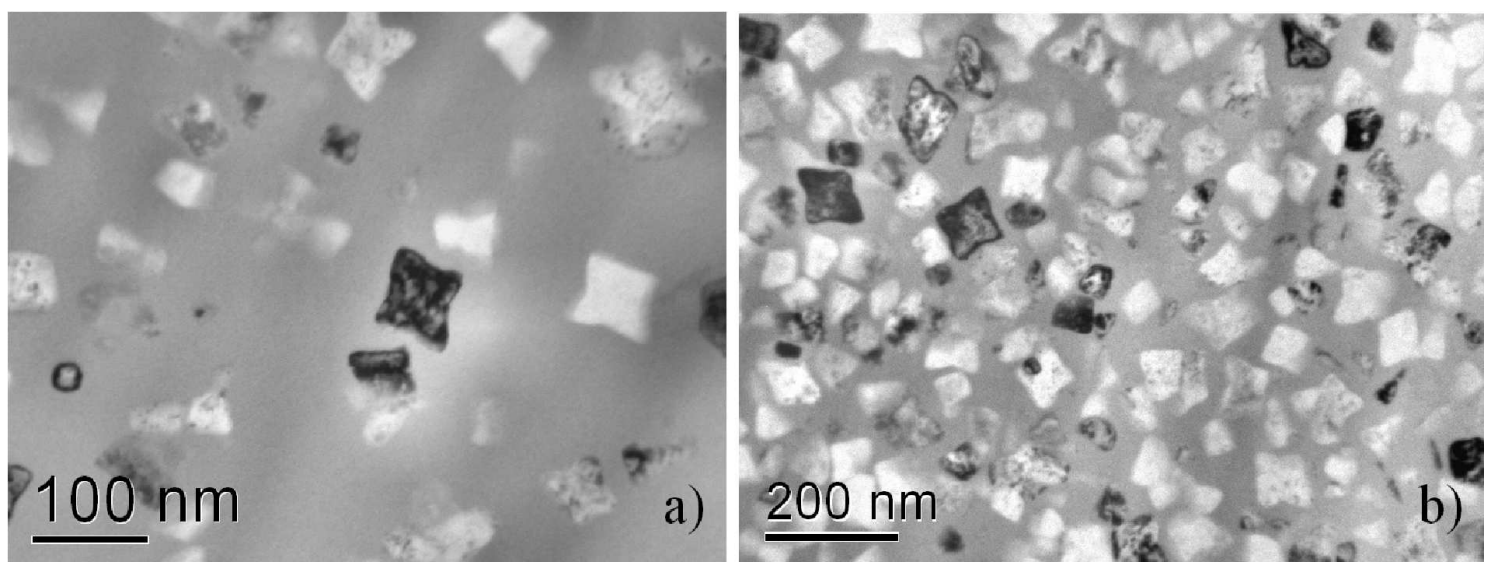

Fig. 6. TEM images showing structure evolution after annealing at $\left.723 \mathrm{~K} / 30 \mathrm{~min} ;(\mathrm{a})-\left(\mathrm{Fe}_{2} \mathrm{Co}_{1}\right)_{81.5} \mathrm{Sn}_{3.5} \mathrm{~B}_{15} ;(\mathrm{b})-\mathrm{Fe}_{1} \mathrm{Co}_{1}\right)_{81.5} \mathrm{Sn}_{3.5} \mathrm{~B}_{15}$
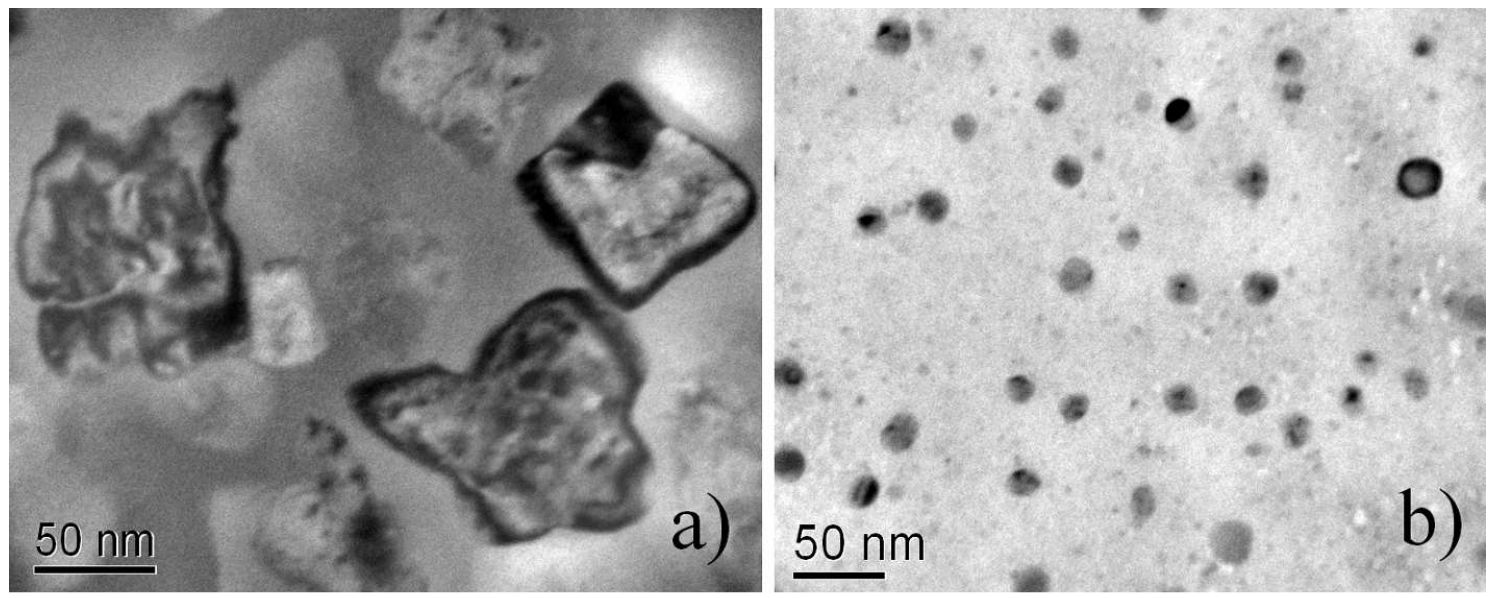

Fig. 7. TEM images showing structure evolution after annealing at $723 \mathrm{~K} / 30 \mathrm{~min} ; \mathrm{a})-\left(\mathrm{Fe}_{2} \mathrm{Co}_{1}\right)_{81.5} \mathrm{Sn}_{3.5} \mathrm{~B}_{15} ;(\mathrm{b})-\left(\mathrm{Fe}_{1} \mathrm{Co}_{1}\right)_{76.5} \mathrm{Sn}_{3.5} \mathrm{~B}_{20}$

phase. Thus the main interest was focused on the first transformation and the ferromagnetic products in amorphous matrix. Diffraction patterns of samples annealed in the vicinity of the first-stage transformation exhibit a slight shift of the bcc-Fe(Co) peaks with Co content towards lower lattice parameters. The ratio of ferromagnetic metals has lower effect on the morphology of this ferromagnetic phase than the increase of metalloid content, but has an important effect on the final phase content after the crystallization of the remaining amorphous matrix. Due to the decreasing interval between $T_{x 1}$ and $T_{x 2}$ with increasing B content resulting in the decreasing stability of the remaining amorphous phase the materials with lower B exhibit higher stability of the bcc structure.

\section{Acknowledgement}

This work was supported by the projects VEGA 2/0189/14, APVV-0492-11, APVV-0460-12 and APVV0076-11 and by the CEX FUN-MAT.

\section{REFERENCES}

[1] HERZER, G. : Acta Materialia 61 (2013), 718-734.
[2] WILlARD, M. A.-DANIIL, M. : Handbook of Magnetic Materials 21 (2013), 173-342.

[3] MAKINO, A. et al: Materials Science and Engineering A 226-228 (1997), 594-602.

[4] MAKINO, A. et al : Journal of Applied Physic 91 No. 10 (2002), 8420-8422.

[5] YOSHIZAWA, Y. et al : Appl. Phys. 64 (1988), 6044.

[6] YOSHIZAWA, Y. et al: Materials Science and Engineering A 375-377 (2004), 207-212.

[7] JANOTOVÁ, I. et al: Journal of Alloys and Compounds 615 (2014), 198-202.

[8] BUTVIN, P. et al: Journal of Alloys and Compounds 509 (2011), 997-1000.

[9] dos SANTOS, C. T. et al : Journal of Magnetism and Magnetic Materials 320 (2008), 183-185.

[10] SHIETAL, M.: Journal of Magnetism and Magnetic Materials 378 (2015), 417-423.

[11] ILLEKOVÁ, E. et al : Journal of Alloys and Compounds 509 (2011), 46-51.

[12] OKAmotO, H. : Phase Diagrams of Binary Iron Alloys (1993), 93-101.

Received 6 June 2015

Irena Janotová (Ing, PhD), Peter Švec, Sr. (Ing, DrSc), Igor Mat'ko (RNDr, CSc), Peter Švec, Jr. (Ing, $\mathrm{PhD}$ ), Dušan Janičkovič (RNDr), Juraj Zigo (Mgr), biographies not supplied. 